\title{
Design of a Continuous Improvement Model in a Portuguese Food Industry Company - A Case Study
}

\author{
Ana Sofia Dias ${ }^{1}$, Helena Victorovna Guitiss Navas², and António João \\ Feliciano Pina da Costa Abreu ${ }^{1}$ \\ ${ }^{1}$ Instituto Superior de Engenharia de Lisboa \\ ${ }^{2}$ Faculdade de Ciências e Tecnologia da Universidade Nova de Lisboa
}

\section{Abstract}

The search for perfection forces organizations to adopt new techniques and approaches, focused on the systematic creation of innovative solutions that facilitate the processes of continuous improvement. In view of this context, there was an opportunity to study the implementation of the Lean philosophy in the production line, at a processed food organization. A continuous improvement model was designed for an organizational system, combining tools used in both TRIZ methodology and Lean

Corresponding Author: Ana Sofia Dias

asdias@dem.isel.ipl.pt

Received: 26 November 2019

Accepted: 13 May 2020

Published: 2 June 2020

Publishing services provided by Knowledge E

(c) Ana Sofia Dias et al. This article is distributed under the terms of the Creative Commons Attribution License, which permits unrestricted use and redistribution provided that the original author and source are credited.

Selection and Peer-review under the responsibility of the ICEUBI2019 Conference Committee.

\section{G OPEN ACCESS} philosophy. Several Lean tools are used in the model in order to support problem formulation, e.g. Brainstorming, 5 Whys, Pareto Diagram, Ishikawa Diagram, Plan-DoCheck-Act (PDCA) Cycle. And the Kano Model integrated in the proposed model allows assessing employee satisfaction at a later stage than the implementation of previously found solutions. In case the problems identified are not very complex, were resorted to the use of both TRIZ and Lean techniques, such as cause/effect databases, the 40 problem solving TRIZ principles, visual management, 5 S's or line balancing. But if the problems identified are more complex, which means with an inventive issue to be solved, Matrix of Contradictions and S-Field Analysis TRIZ tools proved to be more appropriate to find the proper solution. With the case study carried out, it was noted that the proposed model proved to be very useful as a roadmap for the implementation of Lean and TRIZ tools in the continuous improvement of industrial products, services and processes should be the ways to continually minimize them in a company.

Keywords: Continuous improvement, Lean, TRIZ, Management tools, Model proposed

\section{Introduction}

As the global business environment changes, it becomes increasingly difficult to maintain the competitiveness of companies. Customers demand change, technology evolves, and the forces of competitiveness change. The competitive challenge is present in today's business areas because of the competitive characteristics of the markets and the survival principle of the fittest, and who offers obsolete or uncompetitive products, services, concepts or systems will be extinguished [1]. 
Systematic innovation and Lean philosophy can complement each other. Organizations feel the need to make their processes more creative and innovative. The solution generation process is complex, so creative and sometimes disruptive or radical solutions are needed. Thus, in this study was found that, the use of Inventive Problem Solving Theory (TRIZ) within the Lean philosophy, allowed to solve existing problems using its analytical techniques and tools, capable of finding creative solutions [1].

The development of a continuous improvement model aims to combine the techniques of the Lean philosophy, the TRIZ methodology and the Kano Model, in order to find inventive solutions to solve problems of the place under study. The model was developed as a flowchart and forms the basis of the case study performed [1,2]

This paper intends to show the benefits of applying the mentioned methodologies together, in the ham production line of a Portuguese company of processed meat. As a result of the concern to improve its production process and eliminate any kind of waste that is causing expenses, unnecessary for the organization, with the primary objective of maximizing profit by reducing waste, and ensuring quality of service and customer satisfaction.

\section{Importance of Lean Thinking Tools and Methodologies in Manufacturing Processes}

Lean Manufacturing, from a more practical perspective, is the implementation of a set of techniques and tools that aim to reduce waste along the production line. In this investigation work some of these tools and techniques were applied, such as: Visual Management; 5S's and Total Productive Maintenance.

\subsection{Visual Management}

It is a tool with the ability to identify system status in real time [1]. With a focus on facilitating visual communication of information throughout processes, work rules, maintenance and movement, dissemination to all processes or activities within the work environment is strongly suggested [2].

Visual management, sometimes also referred to as visual control, is a process that supports increased efficiency and effectiveness of operations, making things visible, logical and above all more intuitive. Many companies use visual management to make processes simpler, less dependent on computer systems and formal procedures [1]. 
There are various forms of visual control, namely placing frames that signal the quality or control of production, as well as markings delimiting spaces, etc. [3].

According to [2], the objectives of visual management must:

- Be clear and simple, so that there are not many different interpretations between employees;

- Allow workers to be more autonomous and thus make them feel responsible for decision making;

- Facilitate communication between management and operators;

- Allow sharing fundamental information between various levels of the organizational structure.

\subsection{S Methodology}

The 5S Methodology focuses on workplace organization and standardization of work processes in order to make them effective, with a view to simplifying the work environment, reducing waste, eliminating activities that do not add value, increase safety and achieve a higher level of quality efficiency. To implement the 5S methodology is to apply "good habits", despite the simplicity of the concepts and the ease of practical application, its effective implementation is not a simple task, because the essence of the concepts is the promotion of changing people's attitudes and habits [4]. Since this technique was also adopted at Toyota's Production System (TPS), the name of the steps to follow is derived from the Japanese, although today the English nomenclature is used, and they are [5]:

- Sort (SEIRI) - removal of unnecessary items from the work area (materials, machines, equipment, etc.);

- Set in order (SEITON) - "A place for everything and everything in its place" is the sentence that best describes the purpose of this step, always trying to keep the workplace organized;

- Shine (SEISO) - cleaning is necessary for improvement as it enables employees to more easily detect system malfunctions or failures and to work in a clean and operating environment;

- Standardize (SEIKETSU) - after the first three "S's" are implemented, it is necessary to standardize the way of work, betting on the daily work routines imposed by 
the first three steps, always trying to improve the organizational performance in order to "look and recognize the that needs to be done";

- Sustain (SHITSUIKE) - is the most difficult step and consists of maintaining all steps, following all procedures and standards stipulated for this purpose.

According to the same author, although not consensual, some still consider a sixth S - Safety, although this aspect is intrinsic in every aspect of any organization nowadays. The purposes of the $5 S$ Methodology are to improve efficiency by properly disposing of materials (separating what is needed from unnecessary), organizing, cleaning and identifying materials and spaces, maintaining and improving the $5 \mathrm{~S}$ itself. The main benefits of implementing this methodology are [6]:

- Increased productivity by reducing wasted time searching for objects. Only the necessary objects within reach are in the environment;

- Reduction of expenses and better use of materials. Excessive accumulation of materials tends to degenerate;

- Quality improvement of products and services;

- Reduction of work accidents;

- Increasing people's satisfaction with work.

For successful implementation of the $5 \mathrm{~S}$ Methodology, additional efforts are required for its monitoring and evaluation. It is also important that it creates a multi-stakeholder communication platform to improve the entire process [7].

\subsection{Total Productive Maintenance (TPM)}

In order to prevent equipment failures, in the 1980s a new maintenance policy called Predictive Maintenance was developed, which consists in monitoring the condition (functioning) of equipment, assessing its vital signs, using vibrational analysis, noise control, oil analysis, etc. [8]. In this way, the equipment is only intervened when necessary, in a planned way, and whenever possible, in periods of non-production, which leads to significant savings in materials, as it only replaces a certain organ when necessary, and not in the end of a certain period of time (such as Preventive Maintenance), and also leads to increased equipment availability. According to [9], considered the father of TPM, this continuous improvement methodology includes five important elements:

- Maximize equipment efficiency and effectiveness; 
- Develop a productive maintenance system for equipment life;

- Involve in the implementation of TPM, the departments that plan, design, and perform equipment maintenance;

- Involve all company employees, from management members to the lowest hierarchical level of the company;

- Use motivation management as a way to promote PMS by doing autonomous activities in small groups.

In order to implement TPM, eight basic pillars are required [10]. Such pillars are outlined in Figure 1.

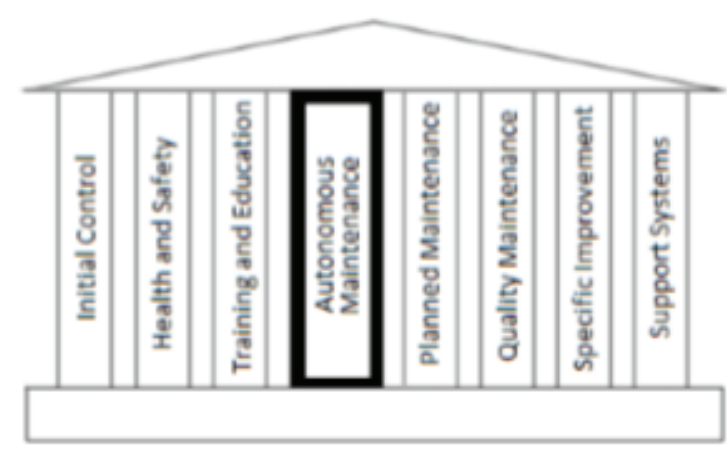

Figure 1: TPM Pillars. Source: [10]

According to [10], each pillar respectively represents the following concepts:

- Initial control of equipment and products - reduces the waste that occurs during the implementation of new equipment or production of a new product;

- Hygiene, safety and environmental control - with the main objective of preventing work accidents and protecting the environment;

- Training - this pillar aims to improve the skills of the operator and the maintainer to increase productivity;

- Structuring autonomous maintenance - the role of the operator is of utmost importance as it performs daily maintenance to prevent equipment degradation;

- Structured planned maintenance - in order to obtain zero failures;

- Quality maintenance - in order to prevent losses;

- Specific improvement - improve machines;

- Support systems - TPM extension to administrative services. 


\section{Inventive Problem Solving Theory (TRIZ)}

This methodology has an acronym of Russian origin Teoriya Resheniya Izobretatelskikh Zadatch (TRIZ) and is a specially adjusted methodology for solving new problems in Science and Engineering [11]. It is considered as a toolkit, used to solve problems and helps to choose the right decision in an inventive and innovative way, replacing the non-systematic trial and error method [12].

The TRIZ was developed by Genrich Saulovich Altshuller (1926-1998), Soviet Russian Navy Engineer and Researcher, who in 1946 reviewed approximately 2.5 million patents from different areas. After this exhaustive analysis, done with the help of his collaborators, Altshuller came to the conclusion that most patents were nothing but system improvements, only a few contained inventions [13].

After systematizing the various patent applications, Altshuller divides them into five levels of innovation, shown in Table 1.

TABLE 1: Innovation Levels. Source: [14]

\begin{tabular}{l|l|l}
\hline $\begin{array}{l}\text { Level } \\
1\end{array}$ & \% & $\begin{array}{l}\text { Description and example } \\
\text { Apparent or conventional solutions using methods known in the art. E.g.: } \\
\text { Increased wall thickness for soundproofing improvement. }\end{array}$ \\
\hline 2 & 45 & $\begin{array}{l}\text { Solutions with minor improvements to existing systems. E.g.: Adjustable } \\
\text { suspension of a vehicle to increase stability. } \\
3\end{array}$ \\
\hline 18 & $\begin{array}{l}\text { Creative solutions capable of resolving contradictions within their respective } \\
\text { branch of engineering. E.g.: Change from manual to automatic transmission in } \\
\text { vehicles. } \\
\text { Solutions found through science. Problems are solved outside the area of expertise } \\
\text { and imply the use of a completely different principle from their primary function. } \\
\text { E.g.: Use of material with thermal memory. Place a key ring in hot water to expand } \\
\text { and facilitate placement of a key so that it can contract at room temperature. } \\
\text { Solutions out of existing knowledge, new scientific discovery. E.g.: The discovery } \\
\text { of laser technology }\end{array}$ \\
\hline 5 &
\end{tabular}

According to [11], TRIZ brings together a set of tools that enable problem solving and help in choosing the most appropriate decision through an innovative and inventive process as an alternative to non-systematic trial and error methods. Thus, for this methodology to be employed, it is important to make some considerations. First, before starting the problem solving process it is necessary to understand if we are in the presence of a problem whose solution is known or totally unknown. In the first case, when problem solving is known, the procedure shown in Figure 2 is adopted.

Looking at Figure 2, the problem at hand is related to a standard problem of a similar nature, which in turn can be solved from a standard solution to which comes a specific solution to the initial problem [12]. 


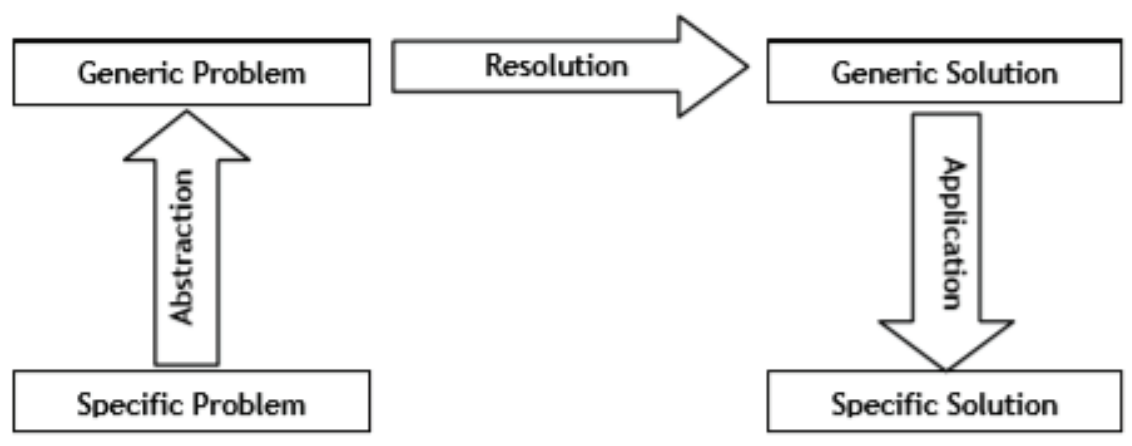

Figure 2: General Problem Solving Process. Source: [12]

Over the last 50 years, TRIZ has become a toolkit that allows to create/invent and solve technical problems with varying levels of complexity. Today it is possible to identify various basic TRIZ tools as well as other methods or techniques that combine with one another to create systematic innovation, such as Lean and TRIZ [13].

\section{Kano Model}

To define specific attributes of a product or service, it is important to define and understand customer needs through market analysis. [15] states that a customer is someone who is affected by a product or process and can be defined as internal or external, which can be considered as belonging to the organization or not belonging to the organization, respectively. A closer way to understand which customer's true needs to be met is by using the Kano model. They need to be objective, otherwise they must be discarded. Using this model allows us to determine customer requirements and expectations by distinguishing six types of attributes of a product or service that influence customer satisfaction [15]:

- Necessary attribute - Failure to complete this attribute will cause the customer to be extremely dissatisfied. Attribute considered as decisive in relation to the competitiveness factor.

- Attractive attribute - requirement that has a great influence on the customer, creating great satisfaction when present. However, if this attribute cannot be reached, there will be no dissatisfaction on the part of it.

- Linear attribute - These attributes are responsible for incremental customer satisfaction, which means, they depend on the weight it has on a particular product or service.

Figure 3 shows the impact of the three main attributes of the Kano model. 


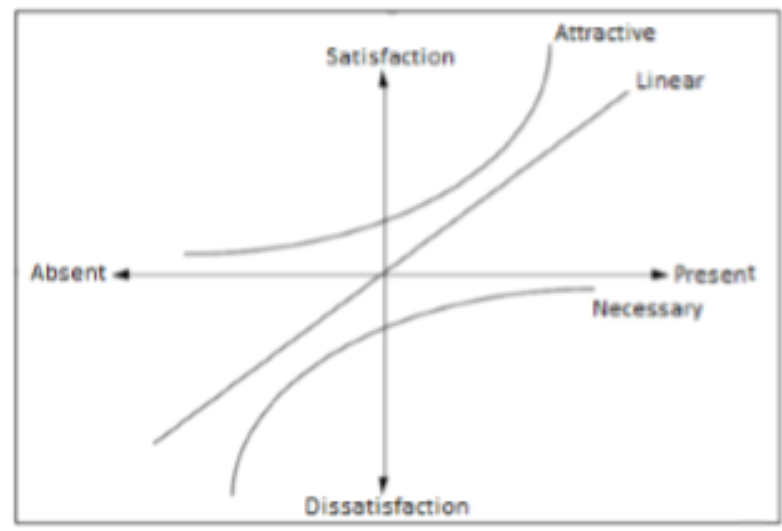

Figure 3: Attributes of the Kano Model [15]

\section{Proposed Model for Continuous Improvement of Prod- ucts and Processes}

The proposed model allows an analysis of a system regarding the existence of waste/contradictions, which means, the existence of a problem. This model outlines and highlights the joint use of the TRIZ methodology with the Lean philosophy to solve problems in an innovative way. The model is in the form of a flowchart and has several alternatives for solving identified problems. Figure 4 presents the representative flowchart of the model proposed in this research work.

The model makes it possible to improve a product/service, essentially using both TRIZ and Lean various tools to find inventive solutions in order to evaluate the improvement proposals/solutions, allowing to understand if the ideality of the system increases and thereby apply them (by reducing resource production costs and reducing damage; for [11], ideality is revealed in an assessment of how close a technical system is to being the best possible).

Several Lean tools are used in the model in order to support problem formulation. And the Kano Model integrated in the proposed model allows assessing employee satisfaction at a later stage than the implementation of previously found solutions.

In case the problems identified are not very complex, were resorted to the use of both TRIZ and Lean techniques, such as cause/effect databases, the 40 problem solving TRIZ principles, visual management, 5S's or line balancing.

But if the problems identified are more complex, which means with an inventive issue to be solved, Matrix of Contradictions and S-Field Analysis TRIZ tools proved to be more appropriate to find the proper solution. 


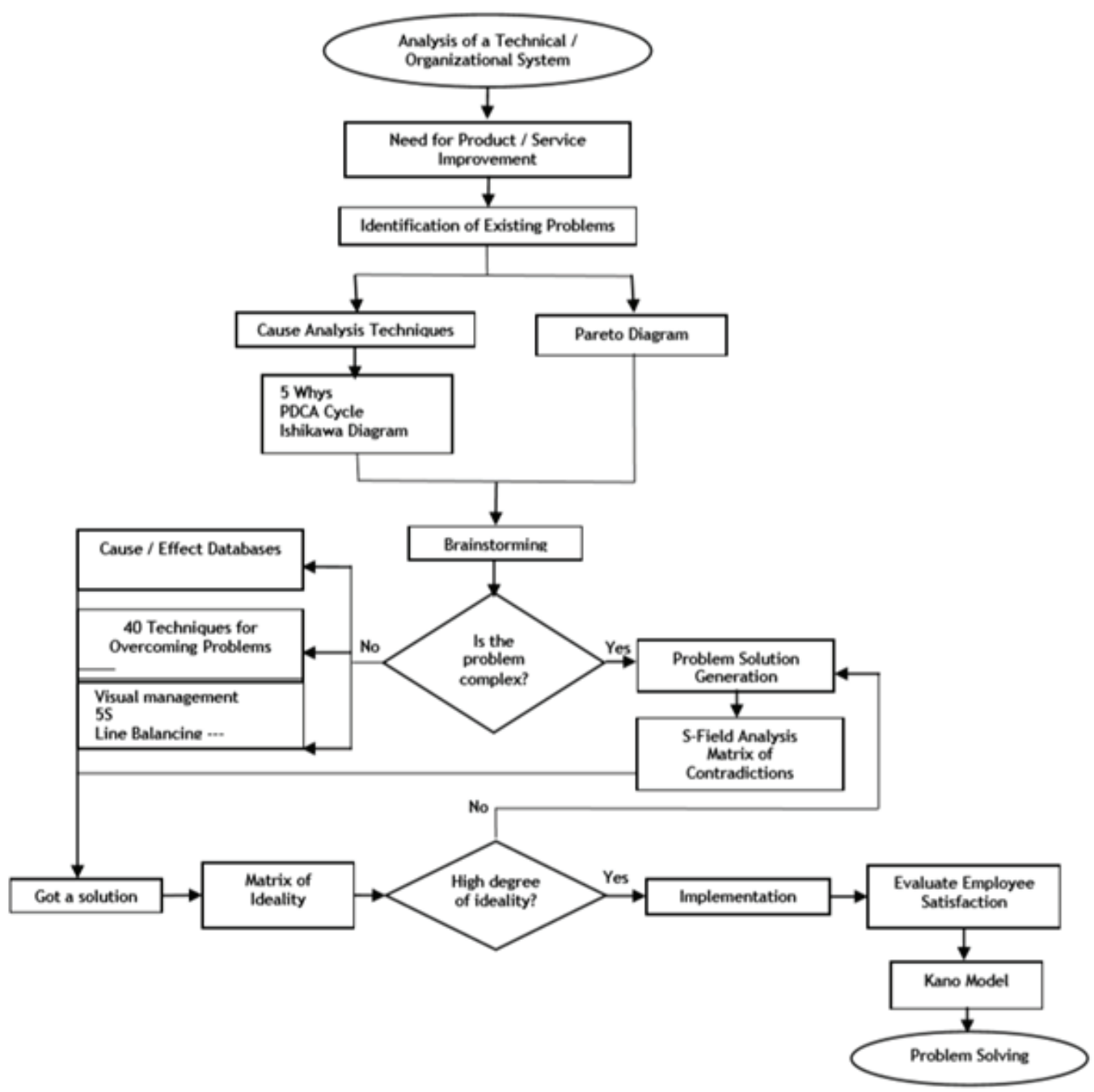

Figure 4: Proposed Model for the Analysis of a Technical/Organizational System

The description of the proposed model was divided into four main phases: analysis of a technical/organizational system; problem solution generation; solution ideality level and employee satisfaction assessment after solution implementation. The systems to which this model can be applied range from technical systems to organizational systems. They can apply to the area of products, processes, organizations, among others.

\section{Case Study}

The case study was conducted at the Portuguese company Nobre Alimentos, Lda.

This case study aimed to detect problems in the ham production line and to point out the correspondent solutions to be implemented. But the use of several Lean and TRIZ tools, involved a considerably high amount of information that turned out to be impossible to present all in this paper, so it will be presented the issues regarding $5 \mathrm{~S}$ 
Lean tool, which has shown to have a condensed way of presenting relevant information. Of course that the issues pointed out with $5 \mathrm{~S}$ tool, before and after the implementation of improvements (tables 2 and 3 ), involved the path pointed out using the model previously presented regarding issues without the necessity of creating disruptive changes (less complex problems). So, a first audit was carried out to identify the problems/points to be improved, as well as to evaluate the current situation of the ham and compare it with the production lines where the methodology had already been applied. Table 2 presents the results of the initial audit performed on the ham production line, and table 3 presents the results of the final audit performed in the same manufacturing process, showing the correspondent improvements occurred to minimize the correspondent problems detected in the first $5 S$ audit. To show the scores obtained, a Likert scale was used with a range of 0 to 10, where 0 means non-existent and 10 means high incidence of the point under study.

The value obtained was $21.4 \%$, and only the 3 S (Organization, Identification, Cleaning) was considered as this tool had never been applied or an analysis had never been developed in this production line. Regarding the Sense of Organization and Identification there was a lot of work to be developed and in terms of Cleaning, as being a food business cleaning the machines and production space is essential, and this was resorted to a subcontractor that manages all company cleaning. Thus, it was decided that the inside of the machines would be cleaned by the workers on a date to be designated. The weight of each control parameter assumes the same weighting factor, with a score of between 0.5 and 10 . Thus, in the initial 3 senses there is a total scale of 140 points.

As can be seen from tables 2 and 3, there was an improvement of 53.6\%, from an initial $21.4 \%$ to $75 \%$. The $5 \mathrm{~S}$ methodology brought several benefits to the line, of which the following should be highlighted:

- Contributes to make employees feel more motivated in their jobs;

- Facilitates and improves equipment maintenance;

- Improves productivity;

- Increases safety and hygiene and health conditions;

- Enables you to get more space in the workplace;

- Allows the company to start new, more complex projects (the production line will always be organized for customer visits, thus helping to promote new business).

On the other hand, the $5 \mathrm{~S}$ was able to involve operational organizing behaviours such as "open, close"; "If I lit, I went out"; "If I call, I hang up"; "Litter, I tidy"; "If dirty, 
TABLE 2: Problems/points to be improved in the first $5 \mathrm{~S}$ audit in the ham production line

\begin{tabular}{|c|c|c|c|c|c|c|}
\hline \multirow[b]{2}{*}{55} & \multirow[b]{2}{*}{$\mathrm{Nr}$} & \multirow[b]{2}{*}{ Evaluation criteria } & \multicolumn{4}{|c|}{ Score } \\
\hline & & & 0 & 5 & 10 & Total \\
\hline \multirow[t]{5}{*}{ Organization } & 1.1 & $\begin{array}{l}\text { Existence of obsolete material in the } \\
\text { production line }\end{array}$ & $x$ & & & 0 \\
\hline & 1.2 & $\begin{array}{l}\text { Existence of unused or defective } \\
\text { materials }\end{array}$ & $x$ & & & 0 \\
\hline & 1.3 & $\begin{array}{l}\text { Existence of unorganized materials, } \\
\text { transport cases or pallets }\end{array}$ & $x$ & & & 0 \\
\hline & 1.4 & $\begin{array}{l}\text { There is unnecessary equipment in } \\
\text { the work area }\end{array}$ & $x$ & & & 0 \\
\hline & 1.5 & $\begin{array}{l}\text { There is unnecessary / irrelevant } \\
\text { information on the desktop }\end{array}$ & $x$ & & & 0 \\
\hline \multirow[t]{4}{*}{ Identification } & 2.1 & $\begin{array}{l}\text { The work areas are identified and } \\
\text { according to the standard }\end{array}$ & & $x$ & & 5 \\
\hline & 2.2 & $\begin{array}{l}\text { There are distinct marks / signs } \\
\text { within the work zone }\end{array}$ & $\mathrm{x}$ & & & 0 \\
\hline & 2.3 & $\begin{array}{l}\text { There are nameplates that } \\
\text { distinguish work zones }\end{array}$ & $\mathrm{x}$ & & & 0 \\
\hline & 2.4 & $\begin{array}{l}\text { There are storage area (cabinet) } \\
\text { identifications }\end{array}$ & $x$ & & & 0 \\
\hline \multirow[t]{6}{*}{ Cleaning } & 3.1 & Access is clear and clean & & & $x$ & 10 \\
\hline & 3.2 & The jobs are clean & & $x$ & & 5 \\
\hline & 3.3 & Work tools / equipment are clean & & & $x$ & 10 \\
\hline & 3.4 & $\begin{array}{l}\text { Are there any cleaning routines / } \\
\text { plans or checklists? }\end{array}$ & $x$ & & & 0 \\
\hline & 3.5 & $\begin{array}{l}\text { All cleaning materials are available } \\
\text { at the workplace }\end{array}$ & $x$ & & & 0 \\
\hline & & & & & & $21.40 \%$ \\
\hline
\end{tabular}

clean"; "If I borrow it, l'll give it back." The $5 \mathrm{~S}$ is, above all, a process that must involve all productive agents, also allowing to change habits and attitudes ending with resistance, favouring change and continuous improvement.

\section{Conclusions}

In a highly competitive market, organizations survival depends on the adoption of innovative practices and methodologies that allow them to overcome competition, continuously improving both their production processes and product quality, taking into account customer needs. So, the implementation of the Lean philosophy, combined with the inventive problem solving techniques of the TRIZ methodology, presupposes the 
TABLE 3: Evaluation of the scores obtained after the implementation of improvements in the last $5 \mathrm{~S}$ audit

\begin{tabular}{|c|c|c|c|c|c|c|}
\hline \multirow[b]{2}{*}{55} & \multirow[b]{2}{*}{$\mathrm{Nr}$} & \multirow[b]{2}{*}{ Evaluation criteria } & \multicolumn{4}{|c|}{ Score } \\
\hline & & & 0 & 5 & 10 & Total \\
\hline \multirow[t]{5}{*}{ Organisation } & 1.1 & $\begin{array}{l}\text { Existence of obsolete material in the } \\
\text { production line }\end{array}$ & & & $x$ & 10 \\
\hline & 1.2 & $\begin{array}{l}\text { Existence of unused or defective } \\
\text { materials }\end{array}$ & & & $x$ & 10 \\
\hline & 1.3 & $\begin{array}{l}\text { Existence of unorganized materials, } \\
\text { transport cases or pallets }\end{array}$ & & & $x$ & 10 \\
\hline & 1.4 & $\begin{array}{l}\text { There is unnecessary equipment in } \\
\text { the work area }\end{array}$ & & $x$ & & 5 \\
\hline & 1.5 & $\begin{array}{l}\text { There is unnecessary / irrelevant } \\
\text { information on the desktop }\end{array}$ & & & $x$ & 10 \\
\hline \multirow[t]{4}{*}{ Identification } & 2.1 & $\begin{array}{l}\text { The work areas are identified and } \\
\text { according to the standard }\end{array}$ & & $x$ & & 5 \\
\hline & 2.2 & $\begin{array}{l}\text { There are distinct marks / signs } \\
\text { within the work zone }\end{array}$ & & & $x$ & 10 \\
\hline & 2.3 & $\begin{array}{l}\text { There are nameplates that } \\
\text { distinguish work zones }\end{array}$ & & & $x$ & 10 \\
\hline & 2.4 & $\begin{array}{l}\text { There are storage area (cabinet) } \\
\text { identifications }\end{array}$ & & & $x$ & 10 \\
\hline \multirow[t]{6}{*}{ Cleaning } & 3.1 & Access is clear and clean & & & $x$ & 10 \\
\hline & 3.2 & The jobs are clean & & $x$ & & 5 \\
\hline & 3.3 & Work tools / equipment are clean & & & $x$ & 10 \\
\hline & 3.4 & $\begin{array}{l}\text { Are there any cleaning routines / } \\
\text { plans or checklists? }\end{array}$ & $x$ & & & 0 \\
\hline & 3.5 & $\begin{array}{l}\text { All cleaning materials are available } \\
\text { at the workplace }\end{array}$ & $x$ & & & 0 \\
\hline & & & & & & $75.00 \%$ \\
\hline
\end{tabular}

creation of innovative solutions to detected problems, creating a competitive advantage for the company.

First, a continuous improvement model was developed, which allowed a logical order to be followed, from problem identification to causes to structure and implementation of improvements that would improve the system's level of ideality, and then to see if they would be beneficial, either, for employees and for the company in general.

Then, a case study was carried out that was always based on the defined model. It was started by monitoring the work day on the production line, and identified several types of problems that could be alleviated using several tools of the LEAN philosophy and TRIZ methodology, such as: cause / effect databases; the 40 problem solving TRIZ principles; visual management; 5S's or line balancing, if the problem did not need a 
disruptive improvement. But otherwise, the Matrix of Contradictions and S-Field Analysis would be the tools to use to improve manufacturing processes.

It was noted that the proposed model proved to be very useful as a roadmap for the implementation of Lean and TRIZ tools in the continuous improvement of industrial products, services and processes should be the ways to continually minimize them in a company.

\section{References}

[1] Pinto, J. P. (2004). Pensamento Lean. (Lisbon: Lidel Edições Técnicas Lda).

[2] Hall, R. W. (1987). Attaining Manufacturing Excellence: Just-in-time, Total Quality, Total People Involvement. (Minnesota: Dow Jones-Irwin).

[3] Shingo, S. (1981). Study of Toyota Production System - from an industrial engineering viewpoint. (New York: CRC Press).

[4] Silva, J. M. (1996). O ambiente da qualidade na prática 5S. (Belo Horizonte: Fundação Christiano Ottoni).

[5] Niebel, B. W. (1994). Engineering Maintenance Management. (USE: CRC Press).

[6] Peterson, J. and Smith, R. (1998). The 5S pocket guide (USA: CRC Press).

[7] Ablanedo-Rosas, J. H., Alidaee, B., Moreno, J. C. and Urbina, J. (2010). Quality improvement supported by the 5S, an empirical case study of Mexican organisations. International Journal of Production, vol. 48, issue 23, pp. 7063-7087.

[8] Rodrigues, M. and Hatakeyama, K. (2006). Analysis of the fall of TPM in companies. Journal of Materials Processing Technology, vol. 179. pp. 276-279.

[9] Genc, S. and Lafortune, S. (2004). Distributed diagnosis of place-bordered petri nets. IEEE Transactions on automation science and engineering, vol. 4, issue 2, pp. 206-219.

[10] Nakajima, S. (1998). Introduction to TPM (USA: CRC Press).

[11] Navas, H. (2013). TRIZ uma metodologia para a resolução de problemas. Guia de Empresas Certificadas, - Comunicação Empresarial, Lda.

[12] Fresner, J., Jantschgi, J., Birkel, S., et al. (2010). The theory of inventive problem solving (TRIZ) as option generation tool within cleaner production projects. Journal of Cleaner Production, vol. 18. Issue 2, pp. 128-136.

[13] Terninko, J., Zussman, A. and Zlotin, B. (19980. Systematic innovation: an introduction to TRIZ. (Florida: St. Lucie Press). 
[14] Glenn, G. (1995). Theory of Inventive Problem Solving (TRIZ). (USA: Springer International).

[15] Lata, C.M. (2002). Modelo Kano de satisfação do cliente: Um estudo de caso para clientes internos. Master’s Dissertaton. (Florianópolis: Universidade Federal de Santa Catarina). 